\title{
Cardiovascular Involvement in Chronic Hepatitis C Virus Infections - Insight from Novel Antiviral Therapies
}

\author{
Wolfgang Poller*1,2 ${ }^{2}$ Arash Haghikia ${ }^{1,2}$, Mario Kasner ${ }^{1}$, Ziya Kaya ${ }^{3,4}$, Udo Bavendiek ${ }^{5}$, \\ Heiner Wedemeier ${ }^{6}$, Hans-Jörg Epple ${ }^{7}$, Carsten Skurk ${ }^{1}$ and Ulf Landmesser ${ }^{1,2}$ \\ ${ }^{1}$ Department of Cardiology, CC11 Charité Campus Benjamin Franklin, Charité - Universitätsmedizin Berlin, Berlin, Germany; \\ ${ }^{2}$ German Center for Cardiovascular Research (DZHK) Site Berlin, Berlin, Germany; ${ }^{3}$ German Center for Cardiovascular Research \\ (DZHK) Site Heidelberg, Heidelberg, Germany; ${ }^{4}$ Department of Cardiology, University Hospital, Heidelberg, Germany; \\ ${ }^{5}$ Department of Cardiology, MHH, Hannover, Germany; ${ }^{6}$ Department of Gastroenterology, MHH, Hannover, Germany; \\ ${ }^{7}$ Department of Gastroenterology, Infectiology and Rheumatology, CC 13, Charité Campus Benjamin Franklin, Charité - \\ Universitätsmedizin Berlin, Berlin, Germany
}

\begin{abstract}
Whereas statistical association of hepatitis C virus (HCV) infection with cardiomyopathy is long known, establishment of a causal relationship has not been achieved so far. Patients with advanced heart failure (HF) are mostly unable to tolerate interferon (IFN)-based treatment, resulting in limited experience regarding the possible pathogenic role of $\mathrm{HCV}$ in this patient group. HCV infection often triggers disease in a broad spectrum of extrahepatic organs, with innate immune and autoimmune pathogenic processes involved. The fact that worldwide more than 70 million patients are chronically infected with HCV illustrates the possible clinical impact arising if cardiomyopathies were induced or aggravated by $\mathrm{HCV}$, resulting in progressive $\mathrm{HF}$ or severe arrhythmias. A novel path has been opened to finally resolve the longstanding question of cause-effect relationship between HCV infection and cardiac dysfunction, by the recent development of IFN-free, highly efficient, and well tolerable anti-HCV regimens. The new direct-acting antiviral (DAA) agents are highly virus-specific and lack unspecific side-effects upon cardiac function which have always confounded the interpretation of IFN treatment data. The actual frequency of unexplained HF in chronic HCV infection will be determined from a planned large-scale study. Whereas such patients probably constitute a rather small fraction of all those harboring $\mathrm{HCV}$, they have major clinical relevance. It is not yet known which fraction of these patients will significantly benefit from HCV
\end{abstract}

Keywords: Autoimmunity; Cardiovascular immunity; Cardiomyopathies; Hepatitis $C$ virus; Antiviral therapies.

Abbreviations: AdV, adenovirus; B19V, parvovirus B19; CAR, coxsackievirusadenovirus-receptor; CI, confidence interval; CLDN1, claudin1; CMP, cardiomyopathy; CVB3, Coxsackievirus B3; CVD, cardiovascular disease; DAA, direct-acting antiviral; DAF, decay accelerating factor; EBV, Epstein-Barr virus; EGFR, EGF receptor; EMBs, endomyocardial biopsies; EphA2, ephedrine A2; ESC, European Society of Cardiology; HCV, hepatitis C virus; HF, heart failure; HHV6, human herpes virus 6; HTA, host targeting agents; HTX, heart transplantation; IFN, interferon; IRES, internal ribosome entry site; LDL-R, LDL receptor; NS, nonstructura protein; OCLN, occludin; $O R$, odds ratio; $P B M C$, peripheral blood mononuclear cell; RdRp, RNA-dependent RNA polymerase; SR-B1, scavenger receptor B1. Received: 22 August 2017; Revised: 6 December 2017; Accepted: 23 December 2017

*Correspondence to: Wolfgang Poller, Department of Cardiology, Campus Benjamin Franklin, Charite Centrum 11, Charité-Universitätsmedizin Berlin, Hindenburgdamm 30, Berlin 12200, Germany. Tel: +49-30-450-513765, Fax: +49-30-450-513984, E-mail: wolfgang.poller@charite.de eradication, but this issue will be addressed now in a prospective study.

Citation of this article: Poller W, Haghikia A, Kasner M, Kaya Z, Bavendiek $\mathrm{U}$, Wedemeier $\mathrm{H}$, et al. Cardiovascular involvement in chronic hepatitis $C$ virus infections - insight from novel antiviral therapies. J Clin Transl Hepatol 2018;6(2):161-167. doi: 10. 14218/JCTH.2017.00057.

\section{Introduction}

Several studies have detected an association of hepatitis $\mathrm{C}$ virus (HCV) infection with cardiomyopathy, but no causal relationship or mechanistic link could be established so far. ${ }^{1-7}$ Importantly, patients with advanced or pretransplant heart failure (HF) as defined by European Society of Cardiology (ESC) guidelines ${ }^{8}$ are mostly unable to tolerate interferon (IFN)-based treatment regimes, resulting in very limited experience with this patient group regarding the possible pathogenic role of $\mathrm{HCV}$ infections. HCV infection often triggers disease in a broad spectrum of extrahepatic organs, ${ }^{9-13}$ with innate immune and autoimmune pathogenic processes being involved, ${ }^{14-16}$ and involvement of the myocardium in HCVtriggered autoimmunity would therefore not come as a surprise. There is no need to assume that HCV directly infects the myocardium, or that HCV impairs the function of a healthy heart and thus constitutes an independent cause of cardiomyopathy and HF. For HCV to have relevance for cardiovascular medicine it would already be sufficient that it indirectly disturbs cardiac function via an immune mechanism, and does so particularly in already injured hearts. In all cases, HCV elimination could result in functional improvement.

The fact that worldwide more than 70 million patients are chronically infected with HCV illustrates the possible clinical impact arising if cardiomyopathies were induced or aggravated by HCV. ${ }^{14,17}$ If progressive HF or severe arrhythmias were induced in even a small fraction of all HCV-positive patients, this would still constitute a grave clinical problem. For this reason, it is most welcome that the long-standing hypothesis of cause-effect relationship between HCV infection and cardiac dysfunction may be conclusively tested now, enabled by the recent introduction of highly efficient and virus-specific direct-acting antiviral (DAA)-based anti-HCV regimens. ${ }^{18-23}$ Cardiac functional effects of DAA-based HCV 
elimination can be directly related to the infection, since the new DAA drugs are devoid of the often grave unspecific side-effects of IFN upon cardiac function. In general, the new regimens may broaden the spectrum of patients eligible for therapy. If these regimens confer significant benefit in cardiovascular or other conditions associated with HCV, extrahepatic HCV manifestations may become an indication for treatment even in the absence of significant liver disease.

\section{Cardiovascular implications of chronic HCV infections}

Whereas HCV is long known as the leading cause of hepatocellular carcinoma and cirrhosis, ${ }^{10}$ the cardiovascular implications of HCV infections are incompletely explored and possible mechanistic links are essentially lacking. Multiple former studies regarding effects of HCV infection upon cardiovascular disease (CVD) risk produced ambiguous results. A recent meta-analysis of these studies ${ }^{10}$ concluded that HCV-infected patients have increased CVD-related mortality (OR: 1.65, 95\% CI: $1.07-2.56, p=0.02$ ), carotid plaques (OR: $2.27,95 \% \mathrm{CI}$ : $1.76-2.94 p<0.001$ ), and cerebrocardiovascular events (OR: $1.30,95 \% \mathrm{CI}: 1.10-1.55, p=0.002$, total 7.611 cerebrocardiovascular events in the HCV group).

Association studies of HCV with cardiomyopathy ${ }^{1-3,24}$ are, by nature, unable to resolve the clinical key question if there is true cause-effect relationship between HCV and cardiac dysfunction. Importantly, not even detection of HCV genomes or their replication ${ }^{4}$ in endomyocardial biopsies (EMBs) can prove causality since HCV might still be an innocent bystander. Against the background of these methodological problems, detailed follow-up of cardiac function and morphology before and after DAA-based HCV eradication offers a very elegant and direct alternative to answer the question.

Using a DAA protocol, we recently found it well tolerated even in a patient with apparently end-stage $\mathrm{HF}^{24} \mathrm{~A}$ patient who was previously unable to tolerate IFN-based anti-HCV therapy as a consequence of grave cardiovascular and psychiatric side-effects had to be listed for heart transplantation (HTX) due inexorable cardiac disease progression. Since HCV-positive status generally excludes successful listing and significantly impairs transplant survival, ${ }^{25,26}$ we subjected her to DAA treatment prior to anticipated HTX. Unexpectedly, she displayed rapid and stable improvement of her NYHA functional status from III-IV before to class II after HCV clearance, and HTX was no longer considered. ${ }^{24}$ The conclusion that HCV was causally involved in her myocardial dysfunction is inevitable for two reasons. First, the DAAs used (ombitasvir, paritaprevir and dasubavir inhibiting viral NS5A protein, RNAdependent RNA polymerase (RdRp) and NS3/4A protease, respectively, plus the CYP3A inhibitor ritonavir) will not eliminate known cardiotropic viruses (coxsackievirus B3 (CVB3), adenovirus (AdV), parvovirus B19 (B19V), human herpes virus 6 (HHV6), Epstein-Barr virus (EBV)) due to the different genome sequences and biological life cycles compared to $\mathrm{HCV}$. Second, for none of the DAAs used a direct effect upon innate or cell-mediated immunity, or upon inflammation in general is known.

Whereas this is an encouraging observation, it is currently not known which fraction of all HCV-infected patients with advanced cardiac dysfunction will experience comparably strong therapeutic benefit from HCV clearance. A large-scale study is thus required to determine the true frequency of the combination of advanced HF with chronic HCV infection. Most likely, patients with severe cardiac dysfunction constitute a rather small fraction of all HCV-positive individuals only, but a subgroup of eminent clinical relevance. A study is therefore planned to recruit a sufficiently large number of HCV-infected patients with cardiac disease who are in need and eligible for state-of-the-art IFN-free HCV elimination therapy. Systematic cardiological follow-up will reveal to what extent and in which fraction of these patients HCV eradication does improve cardiac function. These patients need to be closely monitored for possible side effects (e.g., electrolyte disturbances) ${ }^{24,27}$ since the DAAs are in general well tolerated by nonHF patients, ${ }^{18-22}$ but experience with HF cohorts, especially with patients in advanced stages of HF, is lacking. There have been reports of serious bradycardia among patients treated with sofosbuvir and amiodarone, but systematic review and meta-analysis of pooled data from randomized controlled trials did not show an increased risk of cardiac outcomes. ${ }^{28}$

\section{HCV virology and immunology and possible cardiac pathomechanisms}

After the discovery of $\mathrm{HCV}$ and generation of infectious molecular cDNA clones in $1997,29,30 \mathrm{HCV}$ was classified as prototype Hepacivirus into the Flaviviridae family. HCV constitutes a diversified group of viruses classified into seven genotypes and multiple subtypes, circulating in those infected as continuously evolving quasispecies. ${ }^{17,31,32}$ The same phenomenon, which is based on lack of proof-reading activity of the virusencoded RdRp, is also observed for CVB3, ${ }^{33}$ the prototype virus causing myocarditis and often resulting in dilated cardiomyopathy. ${ }^{34-36}$ For both HCV and CVB3, continuous diversification of virus genome sequences has been documented.

$\mathrm{HCV}$ resembles CVB3 in another important molecular aspect. Both have positive-sense single-stranded RNA genomes which in the host cells serve directly as messenger RNA (Fig. 1B), and in association with modified cell membranes as template for replication through negative-strand full-length intermediates. ${ }^{37,38}$ Both HCV and CVB3 employ internal ribosome entry site (IRES)-mediated translation and polyprotein processing of the long primary virus-encoded mRNA, and both use a particular type of polymerases designated as RdRp, which are important drug targets (Fig. 1B).

The molecular mechanisms of HCV and CVB3 replication therefore display important similarities, whereas tissue tropism and details of replication differ greatly. Cell surface receptors known to be involved in $\mathrm{HCV}$ and CVB3 attachment and internalization are depicted in Fig. 1A. With regard to tissue tropism, it should be noted that this need not be comprehensively determined by the normal receptor complement of target cells, i.e. CVB3 always being targeted to cardiomyocytes or HCV to hepatocytes only. Instead, breakdown of endothelial barriers or alterations of cell surface receptor expression induced by any disease ${ }^{39-43}$ may lead to retargeting of a virus to organs and targets cells normally inaccessible to this specific virus. Thus, one report described the presence of $\mathrm{HCV}$ genomes in the myocardium ${ }^{4}$ by direct analysis of EMBs.

Interferons as primarily host-targeting and rather unspecific therapeutic agents were used for virus suppression or elimination in HCV as well as CVB3 infections. The efficacy of IFN- $\gamma$ was found to be high regarding virus elimination in CVB3 cardiomyopathy patients, resulting in less urgent clinical need for the development of CVB3-specific DAAs. ${ }^{34,44,45}$ This is in sharp contrast to HCV elimination which could not be reached by use of IFN-based regimens, resulting in a high clinical need 


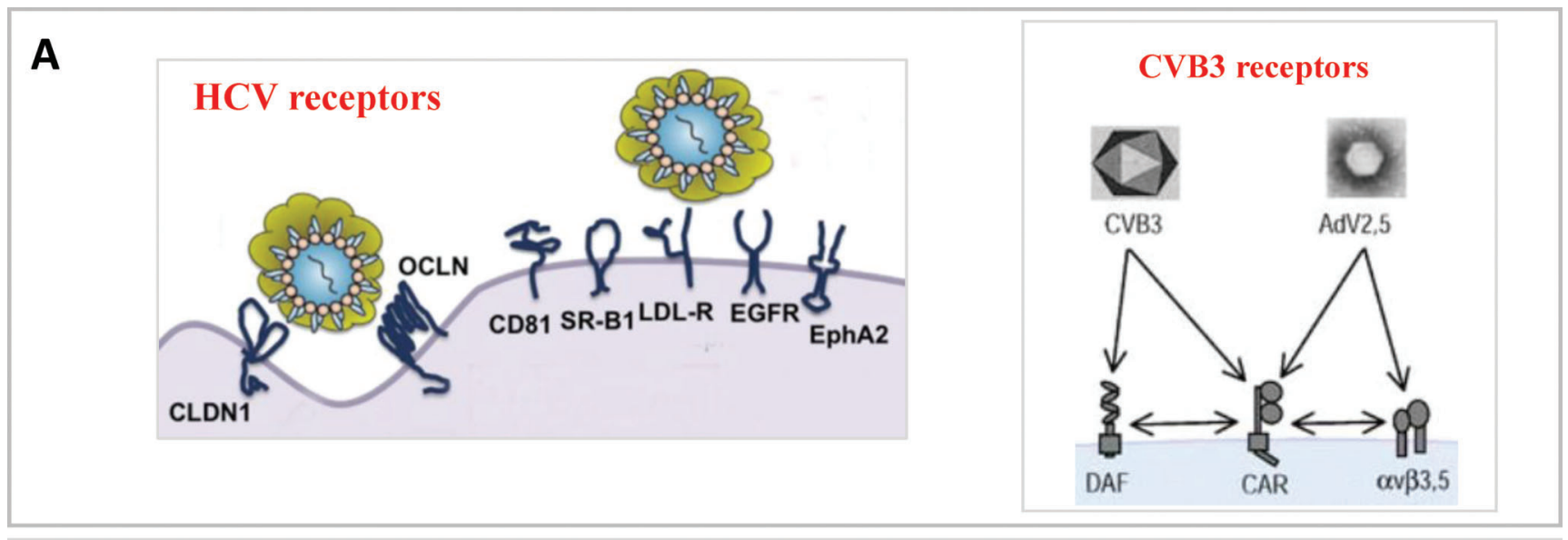

B

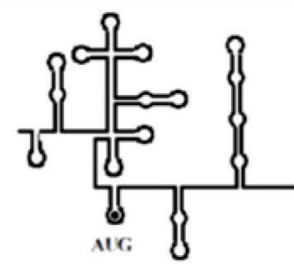

IRES-mediated translation and polyprotein processing

\begin{tabular}{|l|l|l|l|l|l|l|l|l|}
\hline $\mathrm{C}$ & $\mathrm{E} 1$ & $\mathrm{E} 2$ & & $\mathrm{NS} 2$ & $\mathrm{NS} 3$ & $\mathrm{NS} 4 \mathrm{~B}$ & $\mathrm{NS} 5 \mathrm{~A}$ & $\mathrm{NS5B}$ \\
\hline \multicolumn{7}{|c|}{$\mathrm{p7}$} \\
\hline
\end{tabular}

Structural proteins

Non-structural proteins

\section{Key therapeutic targets}

NS3 protease - serin protease, helicase/NTPase, assembly (drugs: telaprevir, boceprevir, simeprevir, paritaprevir, grazoprevir) NS5A - RNA binding, RNA replication, assembly (drugs: elbasvir, ledipasvir, obitasvir, velpatasvir)

NS5B polymerase - RNA-dependent RNA polymerase (nucleoside drugs: sofosbuvir; non-nucleoside drugs: dasabuvir)

Fig. 1. Similarities between the life cycles of $\mathbf{H C V}$ and the prototypical cardiotropic virus CVB3. (A) Cell surface virus receptors determining the tissue tropism of $\mathrm{HCV}$ and CVB3. The molecular mechanisms of HCV and CVB3 replication display important similarities, whereas tissue tropism and details of replication differ. Those cell surface receptors known to be involved in HCV and CVB3 attachment and subsequent receptor-mediated endocytosis are depicted for HCV (left) and CVB3 (right), respectively. It should be noted that these receptors and coreceptors do not irreversibly determine the targeting path of HCV or CVB3 in the host, with CVB3 always reaching cardiomyocytes, and HCV hepatocytes only. Endothelial barrier breakdown or alterations of cell surface receptor expression induced by any disease ${ }^{39-43}$ may lead to retargeting of a virus cell which is normally inaccessible to it. ${ }^{4,39-43}$ (B) The complex intracellular viral genome transcription ultimately leading to HCV replication, and the key therapeutic targets addressed by DAAs. HCV constitutes a divergent group of viruses circulating as continuously evolving quasispecies. ${ }^{17,31,32}$ The same phenomenon, which is based on lack of proof-reading activity of the virus-encoded RdRp, is also observed for CVB3, ${ }^{33}$ the prototype virus causing myocarditis and often resulting in dilated cardiomyopathy. ${ }^{34-36}$ For both HCV and CVB3, continuous diversification of virus genome sequences has been documented. The panel depicts that both HCV and CVB3 have positive-sense singlestranded RNA genomes which in the host cells serve directly as messenger RNA. Both employ IRES-mediated translation and polyprotein processing of the 9.6 kb primary virusencoded mRNA, and both viruses use RdRp for this purpose. The primary 3000 amino acid polyprotein encompasses structural (C - nucleocapsid, E - envelope glycoproteins), as well as non-structural (NS) proteins required for polyprotein processing (NS3 protease) and viral genome transcription and replication (NS5B, RdRp). The RdRp of HCV emerged as an important drug target, which alongside drugs inhibiting the NS3 protease and the NS5A protein form the basis of current IFN-free HCV eradication protocols. Abbreviations: AdV, adenovirus; $\alpha_{v} \beta_{3,5}$, integrins; CAR, coxsackievirus-adenovirus-receptor; CLDN1, claudin1; CVB3, coxsackievirus-adenovirus receptor; DAF, decay accelerating factor; EGFR, EGF receptor; EphA2, ephedrine A2; HCV, hepatitis C virus; IRES, internal ribosome entry site; LDL-R, LDL receptor; NS, non-structural proteins; OCLN, occludin; RdRp, RNA-dependent RNA polymerase; SR-B1, scavenger receptor B1.

for DAAs against HCV. Another, clinically and economically important aspect of the far more intense research into antiHCV DAAs as compared to anti-CVB3 drugs ${ }^{46-51}$ is the fact that CVB3 cardiomyopathy is a rather rare disease, ${ }^{52-60}$ whereas HCV infections are among the most frequent and important viral diseases worldwide. ${ }^{23}$ Millions of patients are newly infected with HCV each year, chronicity rate is high, and over 70 million individuals are known to be infected.

According to current knowledge HCV replicates primarily, if not exclusively, in the patients' hepatocytes, ${ }^{61}$ and its replication is strongly dependent on the liver-specific microRNA-122 which led to the development of a fundamentally novel anti-HCV therapeutic strategy based on an antimiR-122 antagomir (miravirsen). ${ }^{62} \mathrm{~A}$ number of other host molecules critical for HCV entry and replication were identified, ${ }^{21}$ revealing important targets for the development of host targeting agents (HTAs). Although the use of miravirsen in patients with chronic HCV genotype 1 infection resulted in prolonged dose-dependent reductions in HCV RNA levels without evidence of viral resistance, ${ }^{63,64}$ this path is no 
longer followed and has been replaced by DAAs with their significantly higher efficacy and eradication potential. Likewise, none of the several anti-receptor strategies to block attachment and/or internalization of $\mathrm{HCV}^{17}$ or $\mathrm{CVB} 3$ has so far proceeded to the stage of clinical evaluation. ${ }^{31,34,65-70}$
Whereas these studies have addressed host-related molecular mechanisms, other investigations of outstanding importance have addressed the structures and functions of essential HCV-encoded proteins, in particular three of those classified as nonstructural (NS). ${ }^{17}$ The identification and characterization of

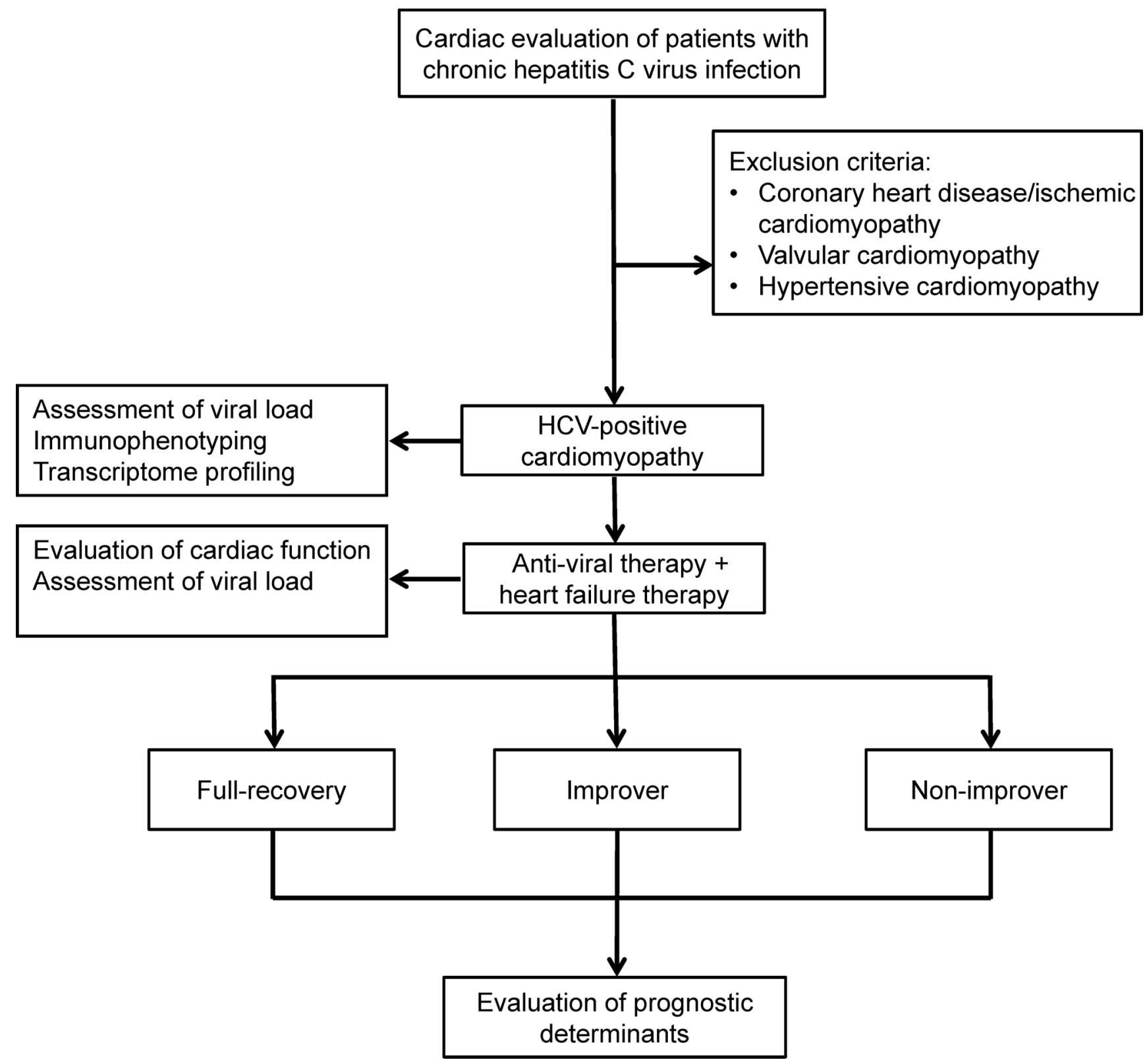

Fig. 2. Study to determine the impact of $\mathbf{H C V}$ eradication upon the course of myocardial diseases. The actual frequency of the combination of cardiomyopathy with chronic HCV infection is currently unknown. This study shall recruit a large number of HCV patients with myocardial disease who are in need and eligible for state-of-the-art HCV eradication. ${ }^{15-18}$ Cardiological follow-up will reveal to what extent, and in which fraction of these patients, HCV eradication does improve cardiac function. For HCV to reach cardiovascular therapeutic relevance it would be sufficient that it indirectly disturbs cardiac function via immune mechanism, even if it does so only or particularly in already preinjured hearts. Therefore, the study shall not only include patients with inexplicable left or right heart dysfunction or morphology, but also patients with nonvalvular and nonischemic cardiomyopathies, and pulmonary hypertension and/or right heart dysfunction of any cause. In these cases, HCV infection may adversely affect the "natural course" of the cardiac disease. The study is primarily based on noninvasive assessment (serial echocardiographies, HF biomarkers) to ascertain the frequency of combination of cardiomyopathy with $\mathrm{HCV}$ infection. In a subgroup of patients with advanced cardiac dysfunction ${ }^{5}$ and/or or extensive morphological anomalies, right/left ventricular EMBs ${ }^{68-70}$ are to be performed in accordance with ESC guidelines. ${ }^{5}$ Patients are classified as IMPs if LVEF increases by 10 absolute percent units or if NYHA improves by one class. Patients are classified as NIMPs if they show at the follow-up visit any of the parameters such as an LVEF $<35 \%$, failure to improve LVEF by 10 absolute units, remaining at a NYHA functional class of III/IV or obtaining heart transplantation/ventricular assist device or if patients die. Full recovery is defined as reaching an LVEF of $>55 \%$ and NYHA class I. Abbreviations: ESC, European Society of Cardiology; EMBs, endomyocardial biopsies; HCV, hepatitis C virus; HF, heart failure; IMPs, improvers; LVEF, left ventricular ejection fraction; NIMPs, nonimprovers. 
HCV-encoded proteins and their functional units enabled the development of highly effective DAAs against the NS3 protease, NS5A and the NS5B polymerase of HCV. As already discussed above, IFN-free regimens based on these DAAs are not only far more efficient than IFN regarding HCV elimination, but they also have far less side effects. In combination, these DAA agents enabled IFN-free therapy with cure rates over $90 \%$ among patients with chronic HCV infection. Nevertheless, viral resistance represents a problem not yet fully solved.

\section{Outlook from the cardiovascular perspective}

\section{Frequency of cardiac dysfunction in chronic HCV infection}

One may safely assume that screening of retrospective series of HCV-positive patients for evidence of unexplained myocardial disease will only detect those with grave myocardial disease. Otherwise either the myocardial disturbance (e.g., isolated diastolic dysfunction) will go undetected, or in cardiological patients there are no data regarding possible HCV infection since there was no clinical hint for liver disease, and hence no apparent need for virus-specific diagnostics. The actual frequency of the combination of cardiomyopathy with chronic $\mathrm{HCV}$ infection therefore shall be determined in a prospective study (Fig. 2).

\section{Cardiovascular therapeutic relevance of $\mathrm{HCV}$ elimination}

In order to proceed beyond the question of frequency to possible cardiovascular therapeutic impact, this study has to recruit a sufficiently large number of HCV patients with cardiac dysfunction who are in need and eligible for stateof-the-art HCV eradication. ${ }^{17-22}$ Careful cardiological followup will then reveal to what extent, and in which fraction of these patients, HCV eradication does in fact improve cardiac function. For HCV to reach cardiovascular therapeutic relevance it would suffice that it indirectly disturbs myocardial function via immune mechanism, even if it does so only or particularly in already pre-injured hearts. There is no need to assume that HCV directly infects the myocardium, or impairs the function of a healthy heart, thus constituting an independent cause of cardiomyopathy and HF. Therefore, the study shall not only include patients with inexplicable left or right heart dysfunction or morphology, but also patients with nonvalvular and nonischemic cardiomyopathies, and with pulmonary hypertension and/or right heart dysfunction of any cause. In these cases, the HCV infection might adversely affect the "natural course" of the cardiac disease.

\section{Persistent immune system anomalies despite successful HCV elimination}

The study is primarily based on noninvasive functional assessment of patients (serial echocardiography, HF biomarkers) which allows to ascertain the frequency of the combination of cardiomyopathy with HCV infection, and to address the question of cardiovascular therapeutic impact. In a subgroup of patients with advanced cardiac dysfunction $^{17-22}$ and/or or extensive morphological anomalies (e.g., massive left/right ventricular hypertrophy), right/left ventricular EMBs ${ }^{71-73}$ are to be performed in accordance with ESC guidelines EMBs, ${ }^{5}$ providing molecular virological data, $4,37,38$ immunohistological data and immune-related gene expression profiles to identify and characterize inflammation, and histology to detect storage diseases. In addition, cardiac autoantibody arrays ${ }^{74-76}$ will be conducted immediately before and 6 months after HCV elimination.

Several sets of data suggest that myocardial dysfunction and pathogenesis in chronically-infected HCV patients are immune-mediated. First, several studies have documented that autoantibodies to myocardial proteins including troponin $\mathrm{I}^{74-76}$ and others ${ }^{74-76}$ may aggravate cardiac dysfunction, and have prognostic relevance. ${ }^{77-79}$ Virus infections induce an innate immune response not only when active viral replication takes place, but also in latent infections with even minimal viral synthesis of immunogenic nucleic acids or proteins. ${ }^{5,80,81}$ In addition to this primordial innate immune activation, there may be virus-triggered autoantibody formation by molecular mimicry or other mechanisms. Second, it has been shown that DAA-induced HCV clearance does not completely restore the altered cytokine and chemokine milieu. ${ }^{82-84}$ From the above immunhistological and serological characterization of the patients before and after virus elimination one may expect further insights into HCV-associated myocardial pathogenesis.

\section{Conflict of interest}

The authors have no conflict of interests related to this publication.

\section{Author contributions}

WP drafted the manuscript which was discussed and improved by all authors. The prospective HCV study described was derived from discussions among the authors all of whom will be involved in this project.

\section{References}

[1] Matsumori A. Hepatitis C virus infection and cardiomyopathies. Circ Res 2005;96:144-147. doi: 10.1161/01.RES.0000156077.54903.67.

[2] Boyella V, Onyebueke I, Farraj N, Graham-Hill S, El Younis C, Bergasa NV. Prevalence of hepatitis $C$ virus infection in patients with cardiomyopathy. Ann Hepatol 2009;8:113-115.

[3] Omura T, Yoshiyama M, Hayashi T, Nishiguchi S, Kaito M, Horiike S, et al. Core protein of hepatitis C virus induces cardiomyopathy. Circ Res 2005;96: 148-150. doi: 10.1161/01.RES.0000154263.70223.13.

[4] Okabe M, Fukuda K, Arakawa K, Kikuchi M. Chronic variant of myocarditis associated with hepatitis $C$ virus infection. Circulation 1997;96:22-24. doi: 10.1161/01.CIR.96.1.22.

[5] Ilyas SZ, Tabassum R, Hamed H, Rehman SU, Qadri I. Hepatitis C virusassociated extrahepatic manifestations in lung and heart and antiviral therapy-related cardiopulmonary toxicity. Viral Immunol 2017;30:633-641. doi: 10.1089/vim.2017.0009.

[6] Demir C, Demir M. Effect of hepatitis C virus infection on the right ventricular functions, pulmonary arterypressure and pulmonary vascular resistance. Int J Clin Exp Med 2014; 7:2314-2318.

[7] Katsi V, Felekos I, Skevofilax S, Aggeli C, Tousoulis D, Stefanadis C, et al. Cardiovascular disease and hepatitis $C$ virus infection: an irrelevant statement or a hot relationship? Cardiol Rev 2015;23:11-17. doi: 10.1097/CRD. 0000000000000031.

[8] Ponikowski P, Voors AA, Anker SD, Bueno H, Cleland JG, Coats AJ, et al. 2016 ESC Guidelines for the diagnosis and treatment of acute and chronic heart failure: The Task Force for the diagnosis and treatment of acute and chronic heart failure of the European Society of Cardiology (ESC). Developed with the special contribution of the Heart Failure Association (HFA) of the ESC. Eur J Heart Fail 2016;18:891-975. doi: 10.1002/ejhf.592.

[9] Voulgaris T, Sevastianos VA. Atherosclerosis as extrahepatic manifestation of chronic infection with hepatitis C virus. Hepat Res Treat 2016;2016: 7629318. doi: $10.1155 / 2016 / 7629318$.

[10] Petta S, Maida M, Macaluso FS, Barbara M, Licata A, Craxì A, et al. Hepatitis $C$ virus infection is associated with increased cardiovascular mortality: 
a meta-analysis of observational studies. Gastroenterology 2016;150:145155.e4. doi: 10.1053/j.gastro.2015.09.007.

[11] Negro F, Forton D, Craxì A, Sulkowski MS, Feld JJ, Manns MP. Extrahepatic morbidity and mortality of chronic hepatitis C. Gastroenterology 2015;149: 1345-1360. doi: 10.1053/j.gastro.2015.08.035.

[12] Soriano V, Labarga P, Fernandez-Montero JV, de Mendoza C, Esposito I, Benítez-Gutiérrez $L$, et al. Hepatitis $C$ cure with antiviral therapy-benefits beyond the liver. Antivir Ther 2016;21:1-8. doi: 10.3851/IMP2975.

[13] Younossi Z, Park H, Henry L, Adeyemi A, Stepanova M. Extrahepatic manifestations of hepatitis C: A meta-analysis of prevalence, quality of life, and economic burden. Gastroenterology 2016;150:1599-1608. doi: 10.1053/j. gastro.2016.02.039.

[14] Gulli F, Basile U, Gragnani L, Fognani E, Napodano C, Colacicco L, et al. Autoimmunity and lymphoproliferation markers in naïve HCV-RNA positive patients without clinical evidences of autoimmune/lymphoproliferative disorders. Dig Liver Dis 2016;48:927-933. doi: 10.1016/j.dld.2016.05.013.

[15] Zignego AL, Gragnani L, Piluso A, Sebastiani M, Giuggioli D, Fallahi $P$, et al. Virus-driven autoimmunity and lymphoproliferation: the example of HCV infection. Expert Rev Clin Immunol 2015;11:15-31. doi: 10.1586/ 1744666X.2015.997214.

[16] Narciso-Schiavon JL, Schiavon Lde L. Autoantibodies in chronic hepatitis C: A clinical perspective. World J Hepatol 2015;7:1074-1085. doi: 10.4254/ wjh.v7.i8.1074.

[17] Bukh J. The history of hepatitis C virus (HCV): Basic research reveals unique features in phylogeny, evolution and the viral life cycle with new perspectives for epidemic control. J Hepatol 2016;65:S2-S21. doi: 10.1016/j.jhep.2016. 07.035 .

[18] Wedemeyer $\mathrm{H}$, Reimer J, Sandow $\mathrm{P}$, Hueppe $\mathrm{D}$, Lutz $\mathrm{T}$, Gruengreiff $\mathrm{K}$, et al. Long-term outcome of chronic hepatitis $C$ virus infection in a real-world setting: The German LOTOS study. Liver Int 2017;37:1468-1475. doi: 10. $1111 /$ liv. 13399

[19] Wedemeyer H, Craxí A, Zuckerman E, Dieterich D, Flisiak R, Roberts SK, et al. Real-world effectiveness of ombitasvir/paritaprevir/ritonavir \pm dasabuvirtribavirin in patients with hepatitis $C$ virus genotype 1 or 4 infection: A meta-analysis. J Viral Hepat 2017;24:936-943. doi: 10.1111/jvh.12722.

[20] Moradpour D, Grakoui A, Manns MP. Future landscape of hepatitis C research Basic, translational and clinical perspectives. J Hepatol 2016;65:S143-S155. doi: $10.1016 / j$.jhep.2016.07.026

[21] Dustin LB, Bartolini B, Capobianchi MR, Pistello M. Hepatitis C virus: life cycle in cells, infection and host response, and analysis of molecular markers influencing the outcome of infection and response to therapy. Clin Microbiol Infect 2016;22:826-832. doi: 10.1016/j.cmi.2016.08.025

[22] Kohli A, Shaffer A, Sherman A, Kottilil S. Treatment of hepatitis C: a systematic review. JAMA 2014;312:631-640. doi: 10.1001/jama.2014.7085.

[23] Global prevalence and genotype distribution of hepatitis $C$ virus infection in 2015: a modelling study. Lancet Gastroenterol Hepatol 2017;2:161-176. doi: 10.1016/S2468-1253(16)30181-9.

[24] Poller W, Kaya Z, Muche M, Kasner M, Skurk C, Kappert K, et al. High incidence of cardiac dysfunction and response to antiviral treatment in patients with chronic hepatitis C virus infection. Clin Res Cardiol 2017;106:551-556. doi: 10.1007/s00392-017-1086-1.

[25] Kumar S, Deo SV, Altarabsheh SE, Dunlay SM, Sarabu N, Sareyyupoglu B, et al. Effect of hepatitis $C$ positivity on survival in adult patients undergoing heart transplantation (from the United Network for Organ Sharing Database). Am J Cardiol 2016;118:132-137. doi: 10.1016/j.amjcard.2016.04. 023.

[26] Belga S, Doucette KE. Hepatitis C in non-hepatic solid organ transplant candidates and recipients: A new horizon. World J Gastroenterol 2016;22:16501663. doi: 10.3748/wjg.v22.i4.1650.

[27] Padegimas A, Forde KA, Goldberg LR, Birati EY. Myo-pericarditis secondary to ledipasvir-sofosbuvir therapy. J Hepatol 2016;64:1196-1198. doi: 10.1016/ j.jhep.2016.01.015.

[28] Caldeira D, Rodrigues FB, Duarte MM, Sterrantino C, Barra M, Gonçalves N, et al. Cardiac harms of sofosbuvir: systematic review and meta-analysis. Drug Saf 2017. doi: 10.1007/s40264-017-0586-2.

[29] Feinstone SM, Kapikian AZ, Purcell RH, Alter HJ, Holland PV. Transfusionassociated hepatitis not due to viral hepatitis type A or B. N Engl J Med 1975;292:767-770. doi: 10.1056/NEJM197504102921502.

[30] Choo QL, Kuo G, Weiner AJ, Overby LR, Bradley DW, Houghton M. Isolation of a CDNA clone derived from a blood-borne non-A, non-B viral hepatitis genome. Science 1989;244:359-362. doi: 10.1126/science.2523562.

[31] Pérez-del-Pulgar S, Gregori J, Rodríguez-Frías F, González P, García-Cehic D, Ramírez S, et al. Quasispecies dynamics in hepatitis C liver transplant recipients receiving grafts from hepatitis C virus infected donors. J Gen Virol 2015;96:3493-3498. doi: 10.1099/jgv.0.000289.

[32] Farci P, Shimoda A, Coiana A, Diaz G, Peddis G, Melpolder JC, et al. The outcome of acute hepatitis $C$ predicted by the evolution of the viral quasispecies. Science 2000;288:339-344. doi: 10.1126/science.288.5464.339.
[33] Domingo E, Martin V, Perales C, Escarmis C. Coxsackieviruses and quasispecies theory: evolution of enteroviruses. Curr Top Microbiol Immunol 2008; 323:3-32. doi: 10.1007/978-3-540-75546-3_1.

[34] Fechner H, Pinkert S, Geisler A, Poller W, Kurreck J. Pharmacological and biological antiviral therapeutics for cardiac coxsackievirus infections. Molecules 2011;16:8475-8503. doi: 10.3390/molecules16108475.

[35] Kuehl U, Lassner D, Gast M, Stroux A, Rohde M, Siegismund C, et al. Differential cardiac microRNA expression predicts the clinical course in human enterovirus cardiomyopathy. Circ Heart Fail 2015;8:605-618. doi: 10 . 1161/CIRCHEARTFAILURE.114.001475.

[36] Kühl U, Lassner D, von Schlippenbach J, Poller W, Schultheiss HP. InterferonBeta improves survival in enterovirus-associated cardiomyopathy. J Am Coll Cardiol 2012;60:1295-1296. doi: 10.1016/j.jacc.2012.06.026.

[37] Pauschinger M, Phan MD, Doerner A, Kuehl U, Schwimmbeck PL, Poller W, et al. Enteroviral RNA replication in the myocardium of patients with left ventricular dysfunction and clinically suspected myocarditis. Circulation 1999;99:889-895. doi: 10.1161/01.CIR.99.10.1348.

[38] Pauschinger M, Bowles NE, Fuentes-Garcia FJ, Pham V, Kühl U, Schwimmbeck $\mathrm{PL}$, et al. Detection of adenoviral genome in the myocardium of adult patients with idiopathic left ventricular dysfunction. Circulation 1999;99: 1348-1354. doi: 10.1161/01.CIR.99.10.1348

[39] Noutsias $M$, Fechner $H$, de Jonge $H$, Wang $X$, Dekkers $D$, Houtsmuller $A B$, et al. Human coxsackie-adenovirus receptor is colocalized with integrins alpha(v)beta(3) and alpha(v)beta(5) on the cardiomyocyte sarcolemma and upregulated in dilated cardiomyopathy: implications for cardiotropic viral infections. Circulation 2001;104:275-280. doi: 10.1161/01.CIR.104. 3.275.

[40] Poller W, Fechner H, Noutsias M, Tschoepe C, Schultheiss HP. Highly variable expression of virus receptors in the human cardiovascular system. Implications for cardiotropic viral infections and gene therapy. Z Kardiol 2002;91: 978-991. doi: 10.1007/s00392-002-0862-7.

[41] Fechner H, Noutsias M, Tschoepe C, Hinze K, Wang X, Escher F, et al. Induction of coxsackievirus-adenovirus-receptor expression during myocardia tissue formation and remodeling: identification of a cell-to-cell contactdependent regulatory mechanism. Circulation 2003;107:876-882. doi: 10 . 1161/01.CIR.0000050150.27478.C5.

[42] Lisewski U, Shi Y, Wrackmeyer U, Fischer R, Chen C, Schirdewan A, et al. The tight junction protein CAR regulates cardiac conduction and cell-cell communication. J Exp Med 2008;205:2369-2379. doi: 10.1084/jem.20080897.

[43] Fischer R, Poller W, Schultheiss HP, Gotthardt M. CAR-diology-a virus receptor in the healthy and diseased heart. J Mol Med (Berl) 2009;87:879-884 doi: 10.1007/s00109-009-0489-5.

[44] McDonald S, Block A, Beaucourt S, Moratorio G, Vignuzzi M, Peersen OB. Design of a genetically stable high fidelity coxsackievirus B3 polymerase that attenuates virus growth in vivo. J Biol Chem 2016;291:13999-14011. doi: $10.1074 /$ jbc.M116.726596.

[45] Lauring AS, Andino R. Exploring the fitness landscape of an RNA virus by using a universal barcode microarray. J Virol 2011;85:3780-3791. doi: 10. 1128/JVI.02217-10.

[46] Kim BK, Ko H, Jeon ES, Ju ES, Jeong LS, Kim YC. 2,3,4-Trihydroxybenzylhydrazide analogues as novel potent coxsackievirus B3 3 C protease inhibitors. Eur J Med Chem 2016;120:202-216. doi: 10.1016/j.ejmech.2016.03.085.

[47] Kim BK, Cho JH, Jeong P, Lee $Y$, Lim JJ, Park KR, et al. Benserazide, the first allosteric inhibitor of Coxsackievirus B3 3C protease. FEBS Lett 2015;589: 1795-1801. doi: 10.1016/j.febslet.2015.05.027.

[48] Song QQ, Lu MZ, Song J, Chi MM, Sheng LJ, Yu J, et al. Coxsackievirus B3 2A protease promotes encephalomyocarditis virus replication. Virus Res 2015 208:22-29. doi: 10.1016/j.virusres.2015.05.020.

[49] Zuo J, Kye S, Quinn KK, Cooper P, Damoiseaux R, Krogstad P. Discovery of structurally diverse small-molecule compounds with broad antiviral activity against enteroviruses. Antimicrob Agents Chemother 2015;60:1615-1626. doi: 10.1128/AAC.02646-15.

[50] Norder H, De Palma AM, Selisko B, Costenaro L, Papageorgiou N, Arnan C, et al. Picornavirus non-structural proteins as targets for new anti-virals with broad activity. Antiviral Res 2011;89:204-218. doi: 10.1016/j.antiviral. 2010.12.007.

[51] Fili S, Valmas A, Christopoulou M, Spiliopoulou M, Nikolopoulos N, Lichière J, et al. Coxsackievirus B3 protease $3 \mathrm{C}$ : expression, purification, crystallization and preliminary structural insights. Acta Crystallogr F Struct Biol Commun 2016;72:877-884. doi: 10.1107/S2053230X16018513.

[52] Schultheiss HP, Piper C, Sowade O, Waagstein F, Kapp JF, Wegscheider K, et al. Betaferon in chronic viral cardiomyopathy (BICC) trial: Effects of interferon- $\beta$ treatment in patients with chronic viral cardiomyopathy. Clin Res Cardiol 2016;105:763-773. doi: 10.1007/s00392-016-0986-9.

[53] Kühl U, Pauschinger M, Bock T, Klingel K, Schwimmbeck CP, Seeberg B, et al. Parvovirus B19 infection mimicking acute myocardial infarction. Circulation 2003;108:945-950. doi: 10.1161/01.CIR.0000085168.02782.2C.

[54] Kühl U, Pauschinger M, Schwimmbeck PL, Seeberg B, Lober C, Noutsias $M$, et al. Interferon-beta treatment eliminates cardiotropic viruses and improves left ventricular function in patients with myocardial persistence of viral 
genomes and left ventricular dysfunction. Circulation 2003;107:2793-2798. doi: 10.1161/01.CIR.0000072766.67150.51.

[55] Kühl U, Pauschinger M, Noutsias M, Seeberg B, Bock T, Lassner D, et al. High prevalence of viral genomes and multiple viral infections in the myocardium of adults with "idiopathic" left ventricular dysfunction. Circulation 2005;111: 887-893. doi: 10.1161/01.CIR.0000155616.07901.35.

[56] Kühl U, Pauschinger M, Seeberg B, Lassner D, Noutsias M, Poller W, et al. Viral persistence in the myocardium is associated with progressive cardiac dysfunction. Circulation 2005;112:1965-1970. doi: 10.1161/CIRCULATIONAHA.105.548156.

[57] Tschöpe C, Bock CT, Kasner M, Noutsias M, Westermann D, Schwimmbeck $\mathrm{PL}$, et al. High prevalence of cardiac parvovirus $\mathrm{B} 19$ infection in patients with isolated left ventricular diastolic dysfunction. Circulation 2005;111:879-886. doi: 10.1161/01.CIR.0000155615.68924.B3.

[58] Kühl U, Lassner D, Pauschinger M, Gross UM, Seeberg B, Noutsias M, et al. Prevalence of erythrovirus genotypes in the myocardium of patients with dilated cardiomyopathy. J Med Virol 2008;80:1243-1251. doi: 10.1002/ jmv. 21187.

[59] Kuhl U, Lassner D, Dorner A, Rohde M, Escher F, Seeberg B, et al. A distinct subgroup of cardiomyopathy patients characterized by transcriptionally active cardiotropic erythrovirus and altered cardiac gene expression. Basic Res Cardiol 2013;108:372. doi: 10.1007/s00395-013-0372-y.

[60] Escher F, Kühl U, Gross U, Westermann D, Poller W, Tschöpe C, et al. Aggravation of left ventricular dysfunction in patients with biopsy-proven cardiac human herpesvirus A and B infection. J Clin Virol 2015;63:1-5. doi: 10. 1016/j.jcv.2014.11.026.

[61] Wieland S, Makowska Z, Campana B, Calabrese D, Dill MT, Chung J, et al. Simultaneous detection of hepatitis $C$ virus and interferon stimulated gene expression in infected human liver. Hepatology 2014;59:2121-2130. doi: 10.1002/hep.26770.

[62] Jopling CL, Yi M, Lancaster AM, Lemon SM, Sarnow P. Modulation of hepatitis C virus RNA abundance by a liver-specific MicroRNA. Science 2005;309: 1577-1581. doi: 10.1126/science.1113329.

[63] Janssen HL, Reesink HW, Lawitz EJ, Zeuzem S, Rodriguez-Torres M, Patel $\mathrm{K}$, et al. Treatment of HCV infection by targeting microRNA. N Engl J Med 2013;368:1685-1694. doi: 10.1056/NEJMoa1209026.

[64] Rupaimoole R, Slack FJ. MicroRNA therapeutics: towards a new era for the management of cancer and other diseases. Nat Rev Drug Discov 2017;16: 203-222. doi: 10.1038/nrd.2016.246.

[65] Fechner H, Pinkert S, Wang X, Sipo I, Suckau L, Kurreck J, et al. Coxsackievirus B3 and adenovirus infections of cardiac cells are efficiently inhibited by vector-mediated RNA interference targeting their common receptor. Gene Ther 2007; 14:960-971. doi: 10.1038/sj.gt.3302948.

[66] Fechner H, Sipo I, Westermann D, Pinkert S, Wang X, Suckau L, et al. Cardiac-targeted RNA interference mediated by an AAV 9 vector improves cardiac function in coxsackievirus B3 cardiomyopathy. J Mol Med (Berl) 2008;86:987-997. doi: 10.1007/s00109-008-0363-x.

[67] Pinkert S, Westermann D, Wang X, Klingel K, Dörner A, Savvatis K, et al. Prevention of cardiac dysfunction in acute coxsackievirus B3 cardiomyopathy by inducible expression of a soluble coxsackievirus-adenovirus receptor. Circulation 2009;120:2358-2366. doi: 10.1161/CIRCULATIONAHA.108.845339.

[68] Werk D, Pinkert S, Heim A, Zeichhardt H, Grunert HP, Poller W, et al. Combination of soluble coxsackievirus-adenovirus receptor and anti-coxsackievirus siRNAs exerts synergistic antiviral activity against coxsackievirus B3. Antiviral Res 2009;83:298-306. doi: 10.1016/j.antiviral.2009.07.002.

[69] Eckstein A, Grössl T, Geisler A, Wang X, Pinkert S, Pozzuto T, et al. Inhibition of adenovirus infections by siRNA-mediated silencing of early and late adenoviral gene functions. Antiviral Res 2010;88:86-94. doi: 10.1016/j. antiviral.2010.08.002.

[70] Stein EA, Pinkert S, Becher PM, Geisler A, Zeichhardt H, Klopfleisch R, et al. Combination of RNA interference and virus receptor trap exerts additive antiviral activity in coxsackievirus B3-induced myocarditis in mice. J Infect Dis 2015;211:613-622. doi: 10.1093/infdis/jiu504.

[71] Escher F, Lassner D, Kühl U, Gross U, Westermann D, Poller W, et al. Analysis of endomyocardial biopsies in suspected myocarditis-diagnostic value of left versus right ventricular biopsy. Int J Cardiol 2014;177:76-78. doi: 10.1016/ j.ijcard.2014.09.071.

[72] Escher F, Kühl U, Lassner D, Stroux A, Westermann D, Skurk C, et al. Presence of perforin in endomyocardial biopsies of patients with inflammatory cardiomyopathy predicts poor outcome. Eur J Heart Fail 2014;16:1066-1072. doi: $10.1002 /$ ejhf. 148 .

[73] Escher F, Kühl U, Lassner D, Stroux A, Gross U, Westermann D, et al. High perforin-positive cardiac cell infiltration and male sex predict adverse longterm mortality in patients with inflammatory cardiomyopathy. J Am Heart Assoc 2017;6:e005352. doi: 10.1161/JAHA.116.005352.

[74] Müller AM, Bockstahler M, Hristov G, Weiß C, Fischer A, Korkmaz-Icöz S, et al. Identification of novel antigens contributing to autoimmunity in cardiovascular diseases. Clin Immunol 2016;173:64-75. doi: 10.1016/j.clim. 2016.09.003.

[75] Kaya Z, Göser S, Buss S], Leuschner F, Ottl R, Li J, et al. Identification of cardiac troponin I sequence motifs leading to heart failure by induction of myocardial inflammation and fibrosis. Circulation 2008;118:2063-2072. doi: 10.1161/CIRCULATIONAHA.108.788711.

[76] Göser S, Andrassy M, Buss SJ, Leuschner F, Volz CH, Ottl R, et al. Cardiac troponin I but not cardiac troponin $\mathrm{T}$ induces severe autoimmune inflammation in the myocardium. Circulation 2006;114:1693-1702. doi: 10.1161/ CIRCULATIONAHA.106.635664.

[77] Leuschner F, Li J, Göser S, Reinhardt L, Ottl R, Bride P, et al. Absence of autoantibodies against cardiac troponin I predicts improvement of left ventricular function after acute myocardial infarction. Eur Heart J 2008;29:1949-1955. doi: 10.1093/eurheartj/ehn268.

[78] Doesch AO, Mueller S, Nelles M, Konstandin M, Celik S, Frankenstein L, et al. Impact of troponin I-autoantibodies in chronic dilated and ischemic cardiomyopathy. Basic Res Cardiol 2011;106:25-35. doi: 10.1007/s00395-010-0126-z.

[79] Doesch AO, Konstandin M, Celik S, Kristen A, Frankenstein L, Hardt S, et al. Effects of protein $A$ immunoadsorption in patients with advanced chronic dilated cardiomyopathy. J Clin Apher 2009;24:141-149. doi: 10.1002/jca.20204.

[80] Goubau D, Deddouche S, Reis e Sousa C. Cytosolic sensing of viruses. Immunity 2013;38:855-869. doi: 10.1016/j.immuni.2013.05.007.

[81] Yan N, Chen ZJ. Intrinsic antiviral immunity. Nat Immunol 2012;13:214-222. doi: $10.1038 /$ ni.2229.

[82] Hengst J, Falk CS, Schlaphoff V, Deterding K, Manns MP, Cornberg M, et al. Direct-acting antiviral-induced hepatitis $C$ virus clearance does not completely restore the altered cytokine and chemokine milieu in patients with chronic hepatitis C. J Infect Dis 2016;214:1965-1974. doi: 10.1093/infdis/ jiw457.

[83] Hengst J, Strunz B, Deterding K, Ljunggren HG, Leeansyah E, Manns MP, et al. Nonreversible MAIT cell-dysfunction in chronic hepatitis $C$ virus infection despite successful interferon-free therapy. Eur J Immunol 2016;46: 2204-2210. doi: 10.1002/eji.201646447.

[84] Owusu Sekyere S, Suneetha PV, Hardtke S, Falk CS, Hengst J, Manns MP, et al. Type I interferon elevates co-regulatory receptor expression on CMVand EBV-specific CD8 T cells in chronic hepatitis C. Front Immunol 2015;6: 270. doi: 10.3389/fimmu.2015.00270. 